\title{
Making the Case for Arizona School Board Training
}

\author{
Daniel W. Eadens ${ }^{1}$, Nicholas Clement ${ }^{1}$, Michael Schwanenberger ${ }^{1} \&$ Danielle M. Eadens ${ }^{1}$ \\ ${ }^{1}$ Northern Arizona University, Flagstaff, USA \\ Correspondence: Daniel W. Eadens, EdD, Associate Professor, Educational Leadership Department, College of \\ Education's International Coordinator, Northern Arizona University, Flagstaff, Arizona, USA. Tel: 928-523-6242.
}

Received: May 6, 2016

doi:10.5430/irhe.v1n2p99
Accepted: May 29, 2016

Online Published: June 23, 2016

URL: http://dx.doi.org/10.5430/irhe.v1n2p99

\begin{abstract}
Some school boards suffer from deep-seated problems (Hess, 2010) and one of the danger signs is too little professional development (Dervarics \& O'Brien, 2011). Unfortunately, extreme minimal requirements to be certified as a board member such as only being a registered voter and a resident (ASBA, 2015; TASB, 2015; CABE, 2015; GSBA, 2015; \& NYSSBA, 2015) coupled with the need for highly specialized skill sets (Rice et al., 2000) leaves a large gap. Lee and Eadens (2014) found this disconnect between minimal board legal qualifications and the multifaceted skills needed to be effective board members creates a highly compelling argument for comprehensive targeted board training and evaluation. This quantitative study compared Arizona districts' grades, the dependent variable, with state sponsored board trainings, the independent variable, during the 2014 school year. Crosstabulation aimed at finding differences greater than chance alone, indicated that districts who did not send board members to trainings, earned less A's and B's, were essentially less (high-performing) than expected and they earned more D's and F's (low-performing) than expected. In contrast, districts who sent more individuals to more trainings earned more A's and B's, (were more high-performing) than expected and they earned less D's and F's (were less low-performing) than expected. Additionally, districts attending more trainings overall had 1) a higher grade mean, 2) benefited by their grades dropping less on average, 3) had a higher average grade percentage, 4) dropped less on average grade percentage, and 5) overall dropped less on average as measured by state letter-grade systems than those districts that opted against sending board members to trainings. The results of this study are insightful, compelling, and highlights the importance of school board preparation and continuing professional development. Findings add to the body of knowledge related to professional development, training, and evaluation of school boards.
\end{abstract}

Keywords: school boards, professional development, educational leadership

\section{Introduction and Background}

Resnick and Bryant (2008) believe that reasons to have elected school boards are so "that decisions affecting children and the school environment are shaped and approved by people who represent the community" and "school boards hold superintendents accountable for managing the schools....school board members, in turn, are themselves accountable to the public" (p. 8). When professionally performed well, this can be an outstanding system that benefits communities. However, there is wide variety of levels of public accountability for ineffective boards and individual board members. Hess (2010) wrote about these frailties of school boards including the challenges for voters to hold elected representatives accountable, disproportional influences, lack of discipline and continuity, and boards operate in isolation from civic leadership. Hess (2010) claims, "School boards possess real virtues, but they also suffer from real and deep-seated problems" and "elected boards have been blamed for a lack of coherence, discipline, and continuity" but, "despite the widespread complaints about board dysfunction and micromanagement, it's not clear that most superintendents see boards as the hindrance that popular critiques suggest" (p. 4).

\section{Purpose and Research Goal}

Therefore, the purpose of this study was to begin to conduct a series of independent and unbiased examinations of Arizona School Board trainings that were performed during the 2014 school year. The goal of the research was to specifically link school boards whose members attended trainings and compare to district performance effectiveness, as measured by a grade designation calculated by the Arizona Department of Education (ADE). The school grade designation, utilized as a dependent variable in this study, was calculated by ADE. 
Based upon the impetus from a Faculty Grants Program award, educational leadership researchers at Northern Arizona University (NAU) collaborated with the Arizona School Board Association (ASBA) to investigate relationships between school boards who attended ASBA trainings and the district effectiveness grade designation. University researchers, along with ASBA professional development staff, agree that the findings of this study could inform critical planning decisions including, marketing, location, and frequency of training.

\section{Theoretical Foundations and Grounding Studies}

There are limited widely accepted specific school board theories, per se'. The researchers examined new and historical theories. Adding to the grounding theory, this study extensively examined evidence from germane literature from documented studies that implicate the importance of school board training and some ramifications for untrained boards.

While it is no secret that many school board members come with their own personal agendas, one related theory unpacked special interests. This theory, the Theory of Misconnaissance or Misrecognition by Educational Leaders, dissected "...how groups and special interests maintain themselves over periods of time" and claims that in a set of practices, misrecognition has to do with ignoring or flat out denying the political and/or economic interests that exist (Bolton, 2013, p. 953). Besides individuals' motives and politics, the key to board success lies in the effectiveness of the group, despite the organization's dynamics. Green and Griesinger (1996) found a "relationship between board performance and organizational effectiveness" by examining 33 activities within nine areas of board responsibilities of nonprofit boards (p. 381). Goodman, Fulbright, and Zimmerman (1997) interviewed ten districts within five states and offered recommendations in many categories including building teamwork and team training. Teamwork is crucial for board collaboration and success.

Dissatisfaction theory is an appropriate theory most related to the phenomenon surrounding school board collaboration and retention. Alsbury (2003) examined board members and superintendent turnover links using data from 176 school districts. He listed evidence that supported the use of dissatisfaction theory, a governance tool, and highlighted the importance between political versus apolitical distinctions. Much of the literature discussions surrounded board turnover mainly focused on dissatisfaction theory. Dissatisfaction theory essentially states that when the community gets dissatisfied enough with the district's performance, they oust board members and the new boards then replace the superintendent. Superintendents may be "four times" more likely to leave a district because they have an opportunity to "move to a larger district" (Grissom \& Andersen, 2012, p. 1150). Regardless of the reasons for disruptions, longevity can lead to stability and more effective governance.

There is a lack of empirical studies and substantial literature regarding the impact of school board members' training and effective board leadership with regard to school district performance. However, after reviewing research descriptions of ineffective boards, Dervarics and O'Brien found that one of the dozen danger signs of school boards is little professional development (2011). The other danger signs were that school boards are:

- "only vaguely aware of school improvement initiatives, and seldom able to describe actions being taken to improve student learning",

- "focused on external pressures as the main reasons for lack of student success, such as poverty, lack of parental support, societal factors, or lack of motivation",

- "offer negative comments about students and teachers",

- "micro-manage day-to-day operations",

- "disregard the agenda process and the chain of command",

- "left out the information flow; little communication between board and superintendent",

- "quick to describe a lack of parent interest in education or barriers to community outreach",

- "looked at data from a blaming perspective, describing teachers, students and families as major causes for low performance",

- "little understanding or coordination on staff development for teachers",

- "slow to define a vision", and

- " "did not hire a superintendent who agreed with their vision". (p. 8)

Some might ponder if these types of deep-seated issues could arise because boards are ill prepared or developed. 
A review of Arizona, Texas, New York, Georgia, and Connecticut's legal requirements regulating candidacy for local public school board found strong similarities. Based on their findings, prospective school board candidates must meet the following qualifications prior to being placed on the election ballot: 1) be a registered voter, and 2) be a resident of the school district in which he or she resides for at least one year. Additionally, most stipulated that if elected, board members cannot be employed by the district in which they live and if elected, they cannot have a spouse employed by the district (ASBA, 2015; TASB, 2015; CABE, 2015; GSBA, 2015; \& NYSSBA, 2015). However, these dismally minimal requirements for board members is in extreme contrast to the very high requirements for teachers, staff, administrators, and superintendents. Often they have rigorous requirements to be highly qualified, endorsed, licensed, board certified, and have a myriad of specific degree requirements.

Although board membership qualifications are clearly minimal, the more serious dichotomy lies in the fact that the legal duties and responsibilities of school board members, summarized by state school board associations, are extensive and highly complex. In most states, statutes require school board members to execute very specific duties. To name only a few, they typically include hiring and evaluating the district superintendent, setting and approving budgets, calling for budget related elections, setting employee salaries, allocating amounts for budgets for constructing new schools, closing failing schools, and adopting curricula (ASBA, 2015). As part of the governing board, along with the superintendent, school board members are also expected to follow and adhere to a strict code of ethics, which are often adopted as formal policies. These codes of ethics tend to address behavior, both inside and outside the boardroom. In a summary for the American School Board Journal, attributes of effective board members often include respecting the oath of office, working as a team, researching issues, asking tough questions, and avoiding a single issue approach (Blumsack \& McCabe, 2015).

The Center for Public Education examined empirical studies from research literature in great depth including meta-analysis, case studies, district comparison studies, and reports and books. They reasonably concluded, "that school boards in high-achieving school districts look very different, and that they often feature characteristics and approaches that differ, from those in lower-achieving districts" (Dervarics \& O'Brien, 2011, p. 4). From this preponderance of information, they established eight characteristics of effective boards:

1). Effective school boards commit to a vision of high expectations for student achievement and quality instruction and define clear goals toward that vision.

2). Effective school boards have strong shared beliefs and values about what is possible for students and their ability to learn, and of the system and its ability to teach all children at high levels.

3). Effective school boards are accountability driven, spending less time on operational issues and more time focused on policies to improve student achievement.

4). Effective school boards have a collaborative relationship with staff and the community and establish a strong communications structure to inform and engage both internal and external stakeholders in setting and achieving district goals.

5). Effective boards are data savvy; they embrace and monitor data, even when the information is negative, and use it to drive continuous improvement.

6). Effective school boards align and sustain resources, such as professional development, to meet district goals.

7). Effective school boards lead as a united team with the superintendent, each from their respective roles, with strong collaboration and mutual trust.

8). Effective school boards take part in team development and training, sometimes with their superintendents, to build shared knowledge, values and commitments for their improvement efforts. (Dervarics \& O’Brien, 2011, p. 5)

A landmark study conducted for the Iowa Association of School Boards (Rice et al. 2000) further illustrates the need for school board members to possess and demonstrate a sophisticated skill set. This study involved interviewing 159 school board members in three high-achieving and three low-achieving districts. Their qualitative data was analyzed and recurring patterns were compared and contrasted. The research team reported similarities that included caring about children, positive superintendent board relationships, and amicable relationships with other board members. Major differences which emerged from this study included high achieving districts' board members having higher expectations for students than low achieving districts' board members. Likewise, higher achieving board members had a deeper understanding and focus on school renewal and continuous improvement than board members in low-achieving districts (Rice, et al., 2000). 
In a more recent study, Lee and Eadens (2014) conducted a quantitative study that compared board behaviors during meetings in high, medium, and low achieving districts using a multivariate analysis of variance, a procedure for comparing multivariate sample means. This study involved researchers observing over 115 videos of board meetings throughout that nation. Lee and Eadens reported statistically significant differences between three groups: low, average, and high-performing districts. Board meetings in low-performing districts were less orderly, along with board members spending less time on agenda items dealing with student achievement than high-performing district boards. Additional findings included low-performing board members were not listening respectfully and had poorer working relationships with the governance team (Lee \& Eadens, 2014). Lee and Eadens' summary indicates that targeted training could greatly enhance governance effectiveness, thus "highly refined and target-enhanced school board training programs might lead to lasting governance success with superintendents in tandem with their board members, and could lead to more effective governance teaming that affects districts, and ultimately, student achievement." (p. 1)

The disconnect between school board member minimal legal qualifications and the multifaceted skills sets, knowledge, and dispositions needed to be effective board members, creates a very compelling argument for comprehensive and on-going board member professional development and evaluation. States, including Arizona, typically have a state school board association or another organization that conducts targeted trainings to improve school boards. Not being naive, board trainers well realize that being a board member requires very extensive and highly complex abilities, perceptive characteristics, ethical behaviors, and sophisticated skill sets to effectively rise to the challenges and ever-increasing responsibilities that board members need today so they do not fall into the dangers of becoming a low-performing board in low-performing district. Ironically, other than a handful of studies not unlike those herein, there simply is not enough rigorous statistical research that consistently evaluates effectiveness of school board trainings linked to districtwide effectiveness.

\section{Research Questions}

The following research question guided the parameters of the study:

1. Does School Board member training have an impact on overall district effectiveness?

$\mathrm{H}_{0} 1$ School Board member training does not impact overall district effectiveness.

\section{Operational Definition}

ADE calculates district grades based on a complex formula which included the following indicators: student mobility, English Language Learner achievement, dropout rate, graduation rate, longitudinal student academic gain, percentage of students meeting or exceeding state tests (A-F Letter Grade Accountability System Technical Manual, 2011).

\section{Method}

\subsection{Sample}

The State of Arizona's auditor general website provides public domain annual district grades performance and effectiveness data. Only regular education districts that received an annual district-wide grade at the time of this analysis that were listed on the auditor general's website, were included in this study so that effectiveness comparisons, via statistical analysis, could occur. One hundred fifty-two school districts were involved in this study's quantitative analysis. Districts' grades were entered as data solely based from displayed information from the state's website school district reports and publications for school year 2013-14. These grades represent the dependent or outcome variable of the data analysis.

Grades were initially coded by the university researchers and one graduate assistant, were independently verified by additional researchers, and input as $\mathrm{A}=5, \mathrm{~B}=4, \mathrm{C}=3, \mathrm{D}=2, \mathrm{~F}=1$. To maintain anonymity, ASBA offered only the number of trainees from each school district for each training during that school year, representing the independent variable. The districts sent school board presidents and other board members, superintendents and assistant superintendents, and a wide variety of other individuals to trainings during school year (SY) 2014. Some districts sent no one to any training while other districts sent many to a variety of state sponsored trainings. For this analysis, districts that sent at least one individual to at least one ASBA training during the year were separated from districts that send no one to any ASBA training during the school year.

\subsection{Limitations and Assumptions}

The data used in this study was delimited to regular pubic school districts in Arizona only; not special, private, or charter districts or districts that do not receive an annual grade. Additionally, this study was limited to only Arizona 
school board trainings data for a single school year that lasted from July 31, 2013 through June 30, 2014, referred to as SY 2014. Researchers in this study realize that during the designated period, some districts might have sent individuals to regional or national school board trainings, other state's trainings, or may have hired consultants to train locally; however, this study did not examine that data. Additionally, the researchers assume accuracy from the data that was displayed on the auditor general's website as well as data from the data provided from ASBA.

\section{Analysis}

In Table 1's crosstabulation, high-performing (represented via 2.00) are districts that earned an A or B overall district grade for SY 2014 and likewise, low-performing districts (represented by 1.00) earned D or F for SY 2014. School districts that did not send anyone to any ASBA trainings during this school year are represented by a " 0 " in the training column; likewise, the column with a "1" represents districts that sent at least one individual to any of ASBA sponsored trainings during this same school year. Districts that did not receive an official grade for SY 2014, even if they sent individuals to trainings, were eliminated from this study because there was no way other efficient and reliable method to compare their effectiveness or academic achievement performance grade.

\subsection{No Training}

The information within the crosstabulation in Table 1, indicates that of the districts that did not send anyone to any ASBA training in SY 2014, earned fewer A's and B's, were essentially less high-performing, than expected (13 earned, compared to 15.3 that would be expected by chance alone). The districts that did not send individuals to training during SY 2014, also earned more D's and F's, were more low-performing, than expected (6 earned, compared to 3.8 expected by chance alone). The implications that might be inferred from this statistical analysis demonstrates that when districts did not send their school board members, superintendents, or others to be trained at an ASBA training, they performed more poorly on the aforementioned measures.

\subsection{Training}

On the contrary, this same analysis in Table 1 illustrates that districts who sent individuals to ASBA trainings in SY 2014, earned more A's and B's, were more high-performing, than expected (109 earned, compared to 106.8 expected by chance alone). These districts that sent individuals to at least one training, earned less D's and F's, and were more low-performing, than expected ( 24 earned, compared to 26.3 expected by chance alone). Another words, overall, districts that sent someone to training fared better with annual district grades in SY 2014. It appears that sending individuals to training in SY 2014 had a positive impact or relationship at the district level. In this case, it does appear to possess face validity and align with the literature that supports professional development, simply stated, trained districts performed better.

Table 1. High low perform * trained not trained crosstabulation

Case Processing Summary

\begin{tabular}{|c|c|c|c|c|c|c|c|}
\hline \multirow{4}{*}{\multicolumn{2}{|c|}{$\begin{array}{l}\text { High vs Low Perform * Trained } \\
\text { vs Not Trained }\end{array}$}} & \multicolumn{5}{|c|}{ Cases } & \\
\hline & & \multicolumn{2}{|c|}{ Valid } & \multicolumn{2}{|c|}{ Missing } & \multicolumn{2}{|c|}{ Total } \\
\hline & & $\mathrm{N}$ & Percent & $\mathrm{N}$ & Percent & $\mathrm{N}$ & Percent \\
\hline & & 152 & $100.0 \%$ & 0 & $0.0 \%$ & 152 & $100.0 \%$ \\
\hline & & & & \multicolumn{3}{|c|}{ Trained Not Trained } & \\
\hline & & & & & 0 & 1 & $\underline{\text { Total }}$ \\
\hline \multirow[t]{4}{*}{ High vs Low Perform } & \multirow[t]{2}{*}{1.00} & \multicolumn{2}{|l|}{ Count } & & 6 & 24 & 30 \\
\hline & & \multicolumn{2}{|c|}{ Expected Count } & & 3.8 & 26.3 & 30.0 \\
\hline & \multirow[t]{2}{*}{2.00} & \multicolumn{2}{|l|}{ Count } & & 13 & 109 & 122 \\
\hline & & \multicolumn{2}{|c|}{ Expected Count } & & 15.3 & 106.8 & 122.0 \\
\hline \multicolumn{2}{|l|}{ Total } & \multicolumn{2}{|c|}{$\begin{array}{l}\text { Count } \\
\text { Expected Count }\end{array}$} & & $\begin{array}{r}19 \\
19.0\end{array}$ & $\begin{array}{r}133 \\
133.0\end{array}$ & $\begin{array}{r}152 \\
152.0\end{array}$ \\
\hline
\end{tabular}

$2.00=$ high performing, $1.00=$ low performing; $0=$ no training, $1=$ training. 
Pearson's Chi-square tests are typically used to indicate the correlation of the results of a crosstabulation of two categorical variables that are independent of each other. Table 2's Chi-squared test can be utilized to effectively determine differences between frequencies that were observed and expected, not specifically examining statistical significance. This can determine if a number in a category differs greatly from the number expected due to sampling variation differences.

Table 2. Chi-Square Tests

\begin{tabular}{|c|c|c|c|c|c|c|c|}
\hline & Value & Df & & & Sig. & $\begin{array}{l}\text { Exact Sig. } \\
\text { (2-sided) }\end{array}$ & $\begin{array}{l}\text { Exact Sig. } \\
\text { (1-sided) }\end{array}$ \\
\hline Pearson Chi-Square & $1.922^{\mathrm{a}}$ & & 1 & .166 & & & \\
\hline Continuity Correction ${ }^{\mathrm{b}}$ & 1.163 & & 1 & .281 & & & \\
\hline Likelihood Ratio & 1.735 & & 1 & .188 & & & \\
\hline Fisher's Exact Test & & & & & & 214 & 141 \\
\hline Linear-by-Linear Association & 1.910 & & 1 & .167 & & & \\
\hline $\mathrm{N}$ of Valid Cases & 152 & & & & & & \\
\hline
\end{tabular}

a. 1 cells (25.0\%) have expected count less than 5. The minimum expected count is 3.75 .

b. Computed only for a $2 \times 2$ table

Table 3 represents analysis of all districts that sent no one to an ASBA training in SY 2014. The first row is the overall mean grade (A-F) of these districts, 3.48 is almost midway between the grades $\mathrm{C}$ and $\mathrm{B}$. The second line is the mean grade difference between the SY 2013 and SY 2014, -.08 indicates that the overall mean grade slightly decreased the second year in 2014. The row labeled Percentage 2014 represents the overall mean grade percentage (74.8) when A was recoded as $90 \%$ or above, B was $80-89 \%$, C was $70=79 \%$, D was $60-69 \%$, and $\mathrm{F}$ was $59 \%$ and below for districts that sent no one to training in SY 2014. The mean grade percentage difference between SY's 2013 to 2014, when districts that received no grade change between these two years were removed, actually decreased the second year by -1.25 , or a quarter of a grade letter decrease (-.25). Although the descriptive statistic, mean, may conceal some valuable information within the data, the row next to last is the mean grade percentage difference between SY's 2013 to 2014 for districts that send no one to a training, -..40.

Table 3. Descriptive statistics for districts that sent none to training

\begin{tabular}{lrrrrr} 
& $\mathrm{N}$ & Minimum & Maximum & Mean & Std. Deviation \\
\hline coded 2014 $\mathrm{a}=5, \mathrm{~b}=4$ & 25 & 1 & 5 & 3.48 & 1.194 \\
Grade Difference & 25 & -3 & 2 & -.08 & .954 \\
High Low Perform & 19 & 1.00 & 2.00 & 1.684 & .477 \\
Percentage2013 & 25 & 60.00 & 90.00 & 75.200 & 10.049 \\
Percentage2014 & 25 & 50.00 & 90.00 & 74.800 & 11.944 \\
Recode GD & 25 & -9.00 & 6.00 & -.240 & 2.861 \\
Nozeros GD percent & 8 & -20.00 & 20.00 & -1.250 & 15.526 \\
Nozeros GD & 8 & -3.00 & 2.00 & -.250 & 1.752 \\
Percentage Difference & 25 & -20.00 & 20.00 & -.400 & 8.406 \\
Valid N (list wise) & 7 & & & & \\
\hline
\end{tabular}

Likewise, analysis of Table 4 represents all of the districts that did send at least one individual to a training in SY 2014. The first row is the overall mean grade (A-F) of these districts, 3.63 is more than midway between the grades $\mathrm{C}$ and B. The second line is the mean grade difference between the SY's 2013 and 2014, -.03 indicates that the overall mean grade slightly decreased the second year in 2014. This decrease is less than the decrease for the districts that send none to training in the previous table. The row entitled Percentage 2014 represents the overall mean grade percentage (76.3) for districts that did send individuals to at least one SY 2014 training. This mean grade percentage is higher than the percentage from the previous table where none were sent to training. The mean grade percentage difference between SY's 2013 to 2014 when districts that received no grade change between these two years were removed, actually decreased the second year by $-1.05 \%$, a tenth of a letter grade decrease (-.10); a smaller decrease than the previous table. The next to last row is the mean grade percentage from SY's 2013 to 2014 for districts that 
did send individuals to training; note, this percentage -.32 is less of a decrease than the districts that did not send individuals to training, as listed in the previous table.

Table 4. Descriptive statistics for training group

\begin{tabular}{lrrrrr}
\hline & & & \multicolumn{3}{c}{ Std. } \\
coded 2014 a $=5$ & 182 & 2 & 5 & 3.63 & .911 \\
Grade Difference & 182 & -1 & 2 & -.030 & .575 \\
High Low Perform & 133 & 1.00 & 2.00 & 1.819 & .386 \\
Percentage 2013 & 182 & 60.00 & 90.00 & 76.648 & 8.161 \\
Percentage 2014 & 182 & 60.00 & 90.00 & 76.318 & 9.113 \\
Recode GD & 182 & -3.00 & 6.00 & -.098 & 1.724 \\
Nozeros GD percent & 57 & -10.00 & 20.00 & -1.052 & 10.296 \\
Nozeros GD & 57 & -1.00 & 2.00 & -.105 & 1.029 \\
PercentageDifference & 182 & -10.00 & 20.00 & -.329 & 5.748 \\
Valid N (list wise) & 38 & & & & \\
\hline
\end{tabular}

Overall, there is a trend in all variables that indicates that grades went down in general in school districts from 2013 to 2014. However, when compared to districts who did not send anyone to training, those districts who sent individuals to trainings:

- had a higher grade mean in 2014 (3.63 for training as compared to 3.48 for no training),

- saw their grades drop less on average (-.03 for training as compared -.08 for no training),

- had a higher average grade percentage when A's were coded as 90, B's as 80, C's as 70, D's as 60, and F's as 50 (76.3187\% for training as compared to $74.8 \%$ for no training),

- dropped less on average grade percentage (-.3297\% for training group, -..4\% for non-training group),

- dropped less on average when only those districts who had grade changes from 2013-2014 were taken into account (-.1053 for training as compared to -.2500 for no training),

- and dropped less on average grade percentage when only those districts who had grade changes from 2013-2014 were taken into account (-1.0526\% for training as compared $-1.25 \%$ for no training).

Essentially, districts that sent school board members to training were more higher performing districts, as measured by state letter-grade system, than those districts that opted against sending school board members to state sponsored trainings.

\section{Conclusion and Recommendation}

In this study, researchers found a relationship between school district effectiveness labels and attendance at state sponsored trainings developed and implemented by the Arizona School Board Association. Results of this study appear to indicate that for increasing amounts of members that school districts send to trainings, there may be a relationship associated with having a higher school effectiveness grade designation. Although the findings of this study did support a connection between school board members attending training and a district effectiveness label, the results do not support a direct causal relationship. There are many other complex factors and extraneous variables involved that were not considered in this limited study. In fact, there remains a sort of chicken or egg question. Does attending state sponsored board trainings assist board members to develop and support policies that promote school effectiveness? Or do districts who are already effective, support a culture which encourages attendance at ASBA trainings? Additionally, another caution is that due to the specificity and limitations of this particular study, it may not be reliably generalized, to other states across the nation without independent analysis, which researchers highly recommend be done.

However, this work is worthwhile and certainly has built a strong case for school board training in Arizona. Although the analytical results are somewhat limited with the particular statistical tools utilized, coupled with the empirical literature gathered, this study provides clear evidence for the foundations of more indepth study linking board training to district effectiveness. Therefore, this initial work is value-added to the literature and the professional body of research that until now, has remained in its infancy. This type of research desperately needed in 
Arizona, especially with the educational rankings and funding at or near the very bottom. With continued and widened similar and more effective research, results can be more reliably generalized to other states across the nation.

\section{Recommendations for Future Studies}

Future research should investigate the chicken or egg phenomenon through carefully crafted qualitative, quantitative, and hybrid methodologies and examine other non-state sponsored board trainings as well as private, charter, and special districts from every state to better understand the importance of board qualification, professional development trainings, and effectiveness. Additionally, more research is needed to illustrate a greater correlation between district achievement and board member trainings, to include online trainings. With more local professional development options and online training availability, which does not require travel (including webinars and virtual meetings), results would likely be considered more meaningful and cost effective.

Because this study has limitations including an inability to control for district wealth, student demographics, and only examined data from state sponsored ASBA training, future research is needed to fill gaps to more fully understanding this larger phenomenon. Although results suggests correlation between board professional development and district/student outcomes, it should be very clear that this research does not show causality, but points to the need for further research. Fundamentally, future studies should determine if better boards attend more trainings or if trainings improves board performance.

\section{Importance and Implications}

This work is critically important and could lead to major changes in the manner and frequency in which school boards are prepared and professionally developed in the USA. Since ultimately, school boards carry the prodigious responsibility of making decisions that impact current and future generations, it seems clear that professionally developing governing boards should be one of the very highest priorities in educational reform today.

It might be unrealistic to devote time and resources to attempt to universally change the minimal legal requirements for becoming a public school board member in each state. Laws impacting local control of schools are extremely difficult to pass and changes in state constitutions can be tantamount to impossible. Raising the minimum qualifications for school board members may never be accomplished. But, a clear case can and should be made to increasing board professional development.

Although school board effectiveness research remains in an early stage, this study supports the need to develop school board policies and practice targeting ongoing board professional development and preparation. Many qualitative studies have examined and noted the need for professional development and suggest "new concepts for board training" to enhance schoolboard-superintendent relationships (Mountford, 2004). Ideally, board trainings should realistically be research and best practice based, highly focused, and specifically target the actual skills, knowledge, and ethical dispositions which support continuous improvement.

Additionally, programs could include a national certification program for school board members that embraces intensive trainings in policy governance. Carver and Carvers' (2006) book, Reinventing Your Board, tout that policy boards should spend a majority of their time learning specifically how to make informed, visionary, and creatively efficacious decisions. Unfortunately, without engaging in training workshops and highly targeted professional development, many board members simply spend their time micro-managing instead of macro-leading.

\section{References}

A-F Letter Grade Accountability System Technical Manual. (2011). Retrieved from http://www.azed.gov/research-evaluation/files/2011/09/final_a-f-tech-manual.pdf

Alsbury, T.L. (2003). Superintendent and school board member turnover: Political versus apolitical turnover as a critical variable in the application of the dissatisfaction theory. Educational Administration Quarterly, 39(5), 667-698.

Arizona School Board Association. (2015). Retrieved from http://www.azsba.org/becoming-a-board-member/

Blumsack, K., \& McCabe, T. (2015). 7 Signs of Effective School Board Members. American School Board Journal. Retrieved

from http://asbj.com/TopicsArchive/SchoolGovernance/7-Signs-of-Effective-School-Board-Members.html

Bolton, C. (2013). Bourdieu's Theory of Misconnaissance or Misrecognition by Educational Leadens. In B. Irby, G. Brown, R. Lara-Alecio, and S. Jackson (Eds.), The Handbook of Educational Theories. Information Age Pub. 
Carver, J., \& Carver, M. (2006). Reinventing Your Board. Jossey \& Bass. San Francisco, CA.

Connecticut Association of Boards of Education. (2015). Wethersfield, CT. Retrieved from http://www.cabe.org/page.cfm?p=64

Dervarics, C., \& O'Brien, E. (2011). Eight characteristics of effective school boards: Full report. Center for Public Education. Retrieved from http://www.centerforpubliceducation.org/Main-Menu/Public-education/Eight-characteristics-of-effective-school -boards/Eight-characteristics-of-effective-school-boards.html

Georgia School Boards Association. (2015). Advocacy and Communications. Lawrenceville, GA. Retrieved from www.gsba.com

Goodman, R. H., Fulbright, L., \& Zimmerman Jr, W. G. (1997). Getting There from Here. School Board-Superintendent Collaboration: Creating a School Governance Team Capable of Raising Student Achievement. ED413651. Educational Research Service, Arlington, VA.

Green, J. C., \& Griesinger, D. W. (1996). Board performance and organizational effectiveness in nonprofit social services organizations. Nonprofit management and leadership, 6(4), 381-402.

Grissom, J. A., \& Andersen, S. (2012). Why superintendents turn over. American Educational Research Journal, 49(6), 1146-1180.

Hess, F. (2010). Weighing the case for school boards: Today and tomorrow. Phi Delta Kappan, 91(6).

Lee, D. E., \& Eadens, D. W. (2014). The problem: Low-achieving districts and low-performing boards. International Journal of Education Policy \& Leadership, 9(3). Retrieved from www.ijepl.org

Mountford, M. (2004). Motives and power of school board members: Implications for school board-superintendent relationships. Educational Administration Quarterly, 40(5), 704-741.

New York State School Boards Association. (2015). Advocacy and Legislative. Lantham, NY. Retrieved from http://www.nyssba.org/about-nyssba/running-for-the-school-board/

Resnick, M. A., \& Bryant, A. L. (2008). School Boards and the Power of the Public. Education and the making of a democratic people, (pp. 161-180). CO: Paradigm Publishers.

Rice, R., Delagardelle, M., Buckton, M., Jons, C., Lueders, W., Vens, M., \& Weathersby, D. (2000). The lighthouse inquiry: School board/superintendent team behaviors in school districts with extreme difference in student achievement. Iowa Association of School Boards. Retrieved from http://www.ia-sb.org/assets/FADFDF72-BE9D-48D7-8CF9-19B823F0CDA1.pdf

Texas Association of School Boards Association. (2015). Legislative. Austin, TX. Retrieved from https://www.tasb.org/Board-Service.aspxds 